\section{Gastric Ascariasis: A Rare Cause of Upper Gastrointestinal Bleeding}

\begin{abstract}
Although it is the most prevalent helminth worldwide, Ascaris lumbricoides rarely invades the stomach. Ascaris infestation may produce gastrointestinal or biliary obstruction, liver abscess, pancreatitis, volvulus, intussusception, acute appendicitis, occult gastrointestinal bleeding, and anemia. We report here on a case of acute upper gastrointestinal bleeding in a patient with gastric ascariasis, an exceedingly rare complication in this type of helminthiasis.
\end{abstract}

A 75-year-old woman was admitted to our intensive care department due to respiratory failure resulting from tetanus. One week after admission, she was submitted to upper gastrointestinal endoscopy because of hematemesis. She had no previous history of drug or alcohol ingestion, peptic ulcer disease, gastrointestinal bleeding, or abdominal surgery. The physical examination revealed pale conjunctiva, generalized muscle contraction, and a wound in the right leg. Laboratory investigations showed a reduced hemo-

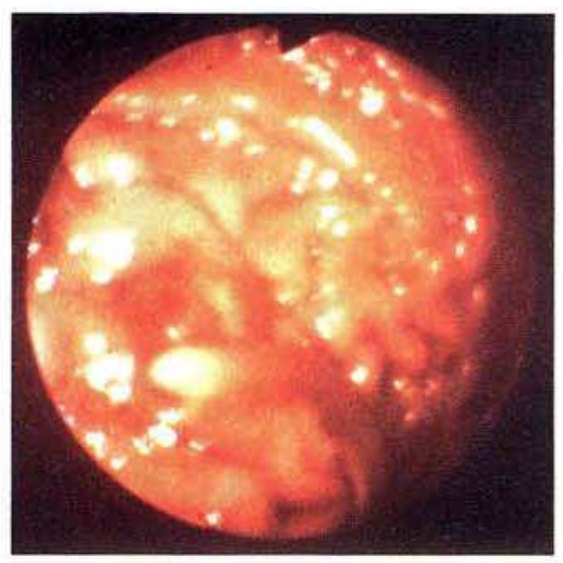

Figure 1: An ascaris worm attached to an erosion on a gastric fold.

globin level $(9.6 \mathrm{~g} / \mathrm{dl})$ and a normal differential leukocyte count. Emergency upper gastrointestinal endoscopy revealed two adult ascaris worms moving in the stomach; one of them was attached to a papulous erosion on a fold in the corpus (Figure 1). There was 


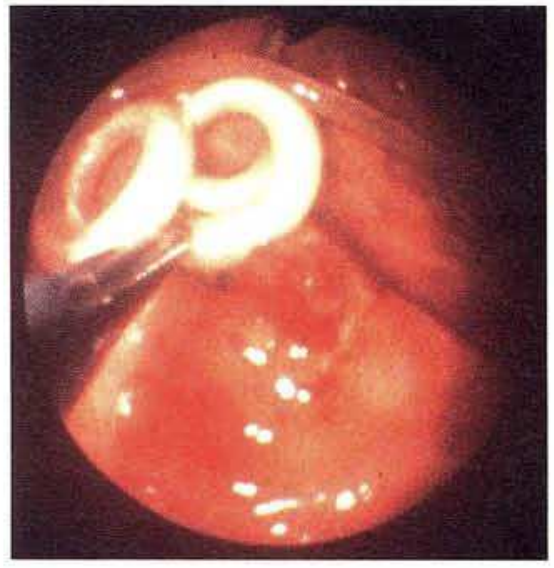

Figure 2: Ascaris lumbricoides caught with an endoscopy forceps.

oozing bleeding from this erosion, and no other lesions were found in the upper gastrointestinal tract. The two worms were removed endoscopically with a forceps (Figure 2). The patient was treated with omeprazole and mebendazole, and there was no rebleeding.

Only three case reports have previously appeared concerning upper gastrointestinal bleeding associated with gastric ascariasis $(1-3)$. The acid environment and the peristaltic activity of the stomach may be responsible for the rarity of gastric ascariasis (4).

This is the first report in which the parasite has been observed attached to an actively bleeding erosion. We presume that this lesion resulted from mechanical trauma produced by the worms, although others have suggested that mucosal irritation by the worm's secretions may also play a role $(3,5)$.
J. M. Pontes', M.C. Leitão', F. Portela', P. Andrade', H. Lopes ',

H. Vasconcelos ', Z. Romão' , J. Pimentel ', A. Donato', D. Freitas ${ }^{1}$

'Dept. of Gastroenterology

${ }^{2}$ Dept. of Intensive Medicine, Coimbra University Hospital,

Coimbra, Portugal

\section{References}

1. Wilairatana P, Wilairatana S, Charoenlarp P. Gastric ascariasis associated with upper gastrointestinal hemorrhage. Southeast Asian J Trop Med Public Health 1994; 25: 401.

2. Bhasin DK, Chinna RS. Hematemesis in gastric ascariasis. Am J Gastroenterol 1989; 84: 1585-6.

3. Jacob GS, Al Nakib B, Al Ruwaih A. Ascariasis producing upper gastrointestinal hemorrhage. Endoscopy 1983; 15: 67.

4. Choudhuri G, Saha SS, Tandon RK. Gastric ascariasis. Am J Gastroenterol 1986; 81: 788-90.

5. Gupta R, Saraswat VA. Endoscopic diagnosis and removal of Ascaris lumbricoides from the stomach. Endoscopy 1993; 25: 378.

Corresponding Author

J. M. Pontes, M.D.

Dept. of Gastroenterology

Coimbra University Hospital

3000 Coimbra

Portugal

Fax:+351-39-70 1517 